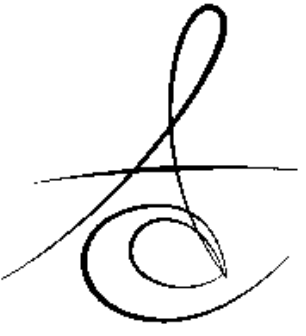

Makale Kodu/Article code: 3489

Makale Gönderilme tarihi: 05.11.2017

Kabul Tarihi: 12.07.2018

\title{
GÜMÜŞ ZEOLİT İLAVE EDİLEN AKRİLİK REZİNLERİN EĞİLME DAYANIMLARININ İN-VITTRO DEĞERLENDİRİLMESİ
}

\section{IN-VITRO EVALUATION OF FLEXURAL STRENGTHS OF ACRYLIC RESINS INCORPORATED SILVER ZEOLITE}

\author{
Sema MURAT DDs, PhD*
}

\section{öz}

Amaç: $\mathrm{Bu}$ çalışmanın amacı, antimikrobiyal ajan olarak farklı ağırlık yüzdeleriyle ilave edilen gümüşzeolitin Isıyla polymerize olan polimetilmetakrilat protez kaidesinin eğilme dayanımına etkisinin ısıl işlem öncesi ve sonrası değerlendirilmesidir.

Gereç ve Yöntem: $64 \times 10 \times 3,3 \mathrm{~mm}$ ebatlarında standart test örnekleri gümüş-zeolitin $\left(\right.$ Zeomic $\left.^{\circledR}\right) \% 0$, $\% 0,5, \% 2$ ve $\% 4$ kuru ağırlık yüzdelerinde ısı ile polimerize olan akrilik tozuna ilave edilmesiyle hazırlanmıştır. Her grup için toplam 20 örnek hazırlanmıştır. Kontrol grubu olarak gümüş-zeolit ilave edilmeyen örnekler kullanılmıştır $(n=20)$. Bu gruplar daha sonra Isıl işlem uygulanmayan ve uygulanan olmak üzere 2 alt gruba $(n=10)$ daha ayrılmıştır. Isıl döngü uygulanan gruptaki örnekler 10000 döngülük ısıl döngü işlemine $\left(5^{\circ} \mathrm{C}\right.$ ve $55^{\circ} \mathrm{C}$ 'de, $30 \mathrm{sn}$ aralıkla) tabii tutulmuşlardır. Eğilme dayanımlarının hesaplanmasında universal test cihazında 3 nokta eğme testi yapılmıştır. Verilerin istatistiksel analizi için Minitab Release 15 yazılım programı ile ANOVA ve bağımlı örneklem t-testi kullanılmıştır. Anlamlılık $\mathrm{p}<0.05$ düzeyinde değerlendirilmiştir.

Bulgular: Isıl döngü işlemi uygulanmayan ve uygulanan grupların her ikisinde de; kontrol grubu (\% 0 ağırlık yüzdesi) diğer üç gruptan istatistiksel olarak anlamlı şekilde daha yüksek eğilme dayanımı gösterirken, ağırlık yüzdesi arttıkça (\% 0,5, \% 2, \% 4) eğilme dayanımı azalmıştır $(p<0.05)$. Bütün gruplar arasındaki farklılık istatistiksel olarak anlamlı bulunmuştur ( $p>0.05)$. Ayrıca ısıl döngü işlemi bütün gruplarda eğilme dayanımını istatistiksel olarak anlamlı şekilde azaltmıştır $(p<0.05)$.

Sonuç: Çalışmamızda gümüş-zeolitin ağırlık yüzdesinin artması ve ısıl döngü işlemi uygulanması ile eğilme dayanımının azalmasına rağmen bulunan değerler ISO 20795-1:2013(E) no'lu standartta belirtilen 65 MPa' dan daha yüksek bulunmuştur.

Anahtar Kelimeler: Akrilik, Eğilme dayanımı, Gümüşzeolit, Isıl döngü işlemi

\section{ABSTRACT}

Aim: The aim of this study was to evaluate the effect of silver-zeolite on flexural strength, which was added into heat polymerized polymethylmethacrylate (PMMA) denture base resin with different percentages as antimicrobial agent before and after thermal cycling.

Material and method: Standard test specimens in sizes of $64 \times 10 \times 3.3 \mathrm{~mm}$ were prepared by adding silver-zeolite (Zeomic ${ }^{\circledR}$ ) into heat polymerized acrylic powder with $0 \%, 0.5 \%, 2 \%$, and $4 \%$ dry weight percentages. A total of 20 samples were prepared for each group. A total of 20 samples without silverzeolite served as the control group. These groups were then divided into 2 subgroups $(n=10)$, a notthermal cycled and thermal cycled group. Samples in thermal cycled group were subjected to 10000 thermal cycling $\left(5^{\circ} \mathrm{C}-55^{\circ} \mathrm{C}\right)$. Three-point FS of the specimens was tested in a universal testing machine and the flexural strength data ( $\sigma$ ) was calculated (MPa). Statistical analysis of the data was performed using the Minitab Release 15 software program by ANOVA and paired t-test. Significance was set at $p<0.05$.

Results: For both groups (non-thermal cycled and thermal cycled), the flexural strength of the control group ( $0 \%$ weight percentage) was significantly higher than the other three groups $(0.5 \%, 2 \%, 4 \%)$ $(p<0.05)$. The differences between other 3 groups were also statistically significant $(p<0.05)$. In addition, for all groups the flexural strength decreased statistically significantly with thermal cycling $(p<0.05)$.

Conclusion: Although an increase in the percentage of silver-zeolite and the application of thermal cycling reduced the flexural strength, our results are still higher than the $65 \mathrm{MPa}$ which is specified in the standard ISO 20795-1: 2013 (E).

Keywords: Acrylic, Flexural strength, Silver-zeolite, Thermal cycling 


\section{GİRİŞ}

Isıyla polimerize olan polimetilmetakrilat (PMMA) rezinler, yüksek toksitite göstermemeleri, biyouyumlu olmaları, estetik kalite ve laboratuvar işlemlerinin kolaylığı ile pahalı olmamaları nedeniyle total ve parsiyel protezlerin hazırlanmasında en yaygın kullanılan protez kaide materyalleridir. ${ }^{1} \mathrm{Bu}$ avantajlarınına rağmen mekanik özelliklerinin çok yüksek olmaması $^{2,3}$ ve mikroorganizmaların biofilm oluşturabilmesi için bir rezervuar görevi görerek ağız dokularında enfeksiyona neden olabilmesi PMMA rezinlerin dezavantajlarıdır. ${ }^{4,5}$ Akrilik protez kaidelerinin yüzeyinde oluşan biofilm porozite, yüzey düzensizliklerinin varlığında daha hızlı oluşmaktadır. Bu nedenle biofilm formasyonunu inhibe edebilen akrilik rezinlerin geliştirilmesi oral candididasis gibi mukozal hastalıkların önlenmesinde kritik öneme sahiptir. ${ }^{6} \mathrm{Bu}$ amaçla kaide polimerlerine antifungal ve antiseptiklerin ilave edilmesi ile antimikrobiyal özellikli polimerlerin üretilmesi güncel yaklaşımlar arasındadır. Parlama-deşarj plazma (glow-discharge plasma) gibi yüzey işlemlerinin uygulanması, polimerlere polar radikallerin katılması, floralkilmetakrilatlar ile kopolimerizasyon sağlanması, alternatif olarak metalik gümüş nanoparti- küllerinin ilavesi ile kaide materyallerine antimikrobiyal özellikler kazandırmaya çalışılmaktadır. ${ }^{7-9}$

Alüminyum silikat kristal yapısına sahip ve içerisinde 3-10 angstrom hava boşluğu içeren antimikrobiyal zeolitler de bu amaçla sıklıkla kullanılmaktadır. ${ }^{7,10}$ Zeolit yapısının içerisindeki boşluklarda bulunan gümüş ve çinko gibi antimikrobiyal katyonlar, zamanla ağız ortamındaki diğer katyonlar ile yer değiştirirler. Serbest katyonlar çevrelerindeki mikroorganizmalarla kontağa geldiğinde mikrobiyal enzimleri inaktive ederek ve RNA replikasyon mekanızmasını bozarak mikroorganizmaların gelişmelerini engellemektedirler. ${ }^{8-11}$ Gümüş-zeolitin, Candida albicans, Streptokokus mutans, Stafilokokus aureus, Stafilokokus epidermis, Pseudomonas aeruginosa ve Escherichia coll ye karşı antimikrobiyal aktivitesini rapor eden çok sayıda çalışma mevcuttur. ${ }^{9-11,17}$ Uzun süre devam eden antimikrobiyal aktiviteleri, düşük toksitite göstermeleri ve tatsız ve kokusuz olmaları nedeniyle zeolitler geniş bir uygulama alanına sahip olmalarına rağmen uygulanabilirlikleri materyalin fiziksel, mekanik ve biyolojik özelliklerini geliştirmesine veya korumasına bağlıdır. ${ }^{11}$

Hareketli bölümlü ve total protez kaideleri ağız ortamında tekrar eden eğilme kuvvetlerine maruz kaldıklarından dolayı oluşan fonksiyonel deformasyon neticesinde orta hat kırıkları ortaya çıkabilmektedir. Bu nedenle kaide rezinlerinin özellikle eğilme dayanımları gibi mekanik özellikleri protezlerin başarısında büyük önem taşımaktadır. Antimikrobiyal özellik kazandırmak için ilave edilen modifiye edici ajanların rezinlerin mekanik özellikleri üzerine etkisinin değerlendirilmesi, materyallerin direncinin azaltılmasının önlenmesinde önem taşımaktadır. $\mathrm{Bu}$ in-vitro çalışmada farklı oranlarda antimikrobiyal gümüş-zeolit içeren ısıyla polimerize akrilik rezinlerin eğilme dayanımlarının incelenmesi amaçlanmıştır.

\section{GEREÇ VE YÖNTEM}

In-vitro çalışmamızda kullanılan test örnekleri 64x10x3,3mm ebatlarında, ISO 20795-1: 2013(E) ${ }^{18}$ no'lu standarda uygun olarak hazırlanmıştır. Antimikrobiyal ajan olarak gümüş-zeolit içerikli Zeomic ${ }^{@}$ AJION (Shinagawa Fuel Ltd., Nagoya, Japonya) seçilmiştir.

Gümüş-zeolit, ISI ile polimerize olan akrilik tozuna (Meliodent, Bayer Dental, Berkshire, İngiltere), $\% 0, \% 0.5, \% 2$ ve $\% 4$ kuru ağırlık yüzdelerinde karıştırılarak üretici firmanın talimatları doğrultusunda uygun toz-likit oranı kullanılarak polimerize edilmişlerdir. \% 0 zeomic ilave edilen grup kontrol grubu olarak kullanılmıştır. Her grup için toplam 20 örnek hazırlanmıştır. Bu gruplar daha sonra ısıl işlem uygulanmayan ve uygulanan olmak üzere de 2 alt gruba $(n=10)$ ayrılmıştır.

Test örneklerinin kenarlarına gerekli tesviye işlemleri yapıldıktan sonra örneklerin yüzeyleri su altında sırasıyla 120, 400, 600, 800 grid'lik aşındırıcı kâğıtlar kullanılarak zımparalanmış ve polisaj pastası ile yüzeyleri parlatılmıştır. Tüm örneklerin kalınlığı bu işlemler sonunda 3,3 $\pm 0,2 \mathrm{~mm}$ 'lik standart kalınlıkta hazırlanmıştır (Resim 1).

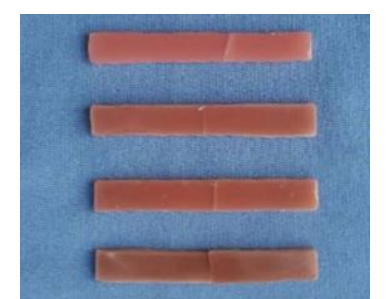

Resim1. Gruplara göre 3 nokta eğme testi ile kırılmış olan örnekler

Antimikrobiyal gümüş-zeolit içeren akrilik rezinlerin eğilme dayanımları üzerinde uzun dönem kullanımda ağız ortamının oluşturduğu etkiyi de 
değerlendirmek amacıyla her gruptaki test örneklerinin yarısına 10000 döngülük ısıl işlem $\left(5^{\circ} \mathrm{C}\right.$ ve $55^{\circ} \mathrm{C}^{\prime} \mathrm{de}$, $30 \mathrm{sn}$ aralıkla) uygulanmıştır.

Bütün gruplardaki örnekler eğilme dayanımı testi öncesinde 48 saat distile su içerisinde $37^{\circ} \mathrm{C}^{\prime}$ de bekletilmişlerdir.

Çalışmamızda materyallerin eğilme dayanımlarının değerlendirilmesi için 3 nokta eğme testi Ankara Üniversitesi Diş Hekimliği Fakültesi Araştırma Laboratuvarında bulunan Lloyd LRX (Lloyd Instruments Ltd., Fareham Hampshire, İngiltere) universal test cihazı ile yapılmıştır. Elde edilen veriler Nexygen (Lloyd Instruments Ltd) yazilımı ile otomatik olarak kaydedilmiştir.

Örneklerin yerleştirilmesinde kullanılan destekler arası mesafe $50 \mathrm{~mm}$ ve cihazın kırma hızı 5 $\mathrm{mm} / \mathrm{sn}$ olacak şekilde ayarlanmıştır. Her bir örneğin kırıması için gerekli olan maksimum kuvvet ve örneğin kırılmadan önce gösterdiği bükülmenin derecesi cihaza bağlı olan bilgisayar sistemi aracılığıyla kaydedilmiştir. Elde edilen değerlerin aşağıdaki formüle uygulanması ile eğilme dayanımı hesaplamaları $\mathrm{MPa}\left(\mathrm{N} / \mathrm{mm}^{2}\right)$ cinsinden yapılmıştır.

$\mathrm{Fs}=$ Eğilme dayanımı $\left(\mathrm{N} / \mathrm{mm}^{2}\right)$

$\mathrm{Fs}=3 \mathrm{FL} / 2 \mathrm{bd}^{2}$

$\mathrm{F}=$ Kırılma anındaki yük $(\mathrm{N})$

$\mathrm{L}=$ Örnek yerleştirilen destekler arasındaki uzaklık (mm)

$\mathrm{b}=$ Örnek genişliği $(\mathrm{mm})$

$\mathrm{d}=$ Örnek kalınlığı $(\mathrm{mm})$

İstatistiksel analiz için veriler, Minitab Release

15 (Minitab Ltd., Pensilvanya, ABD), istatistiksel yazılım programına aktarılmıştır. Materyal ve ısıl döngü işleminin eğilme dayanımı üzerindeki ortak etkisinin değerlendirilmesinde Varyans analizi kullanılmıştır. Gruplar arasındaki farkllıkların analiz edilmesinde ise bağımlı örneklem t-testi (paired t-test) uygulanmıştır. Anlamlıık $p<0.05$ düzeyinde değerlendirilmiştir.

\section{BULGULAR}

Isıl döngü işlemi uygulanmayan gruplarda, kontrol grubu (\% 0 ağırlık yüzdesi) $(149,23 \mathrm{MPa})$ diğer üç gruptan istatistiksel olarak anlamlı şekilde daha yüksek eğilme dayanımı gösterirken, grup 4 (\% 4 ağırlık yüzdesi) ise en düşük eğilme dayanımı (86.66 $\mathrm{MPa})$ göstermiştir $(p<0.05)$. Bütün gruplar arasındaki eğilme dayanımı değerleri arasındaki farklılık istatistiksel olarak anlamlı bulunmuştur (Şekil 1), $(p<0.05)$.

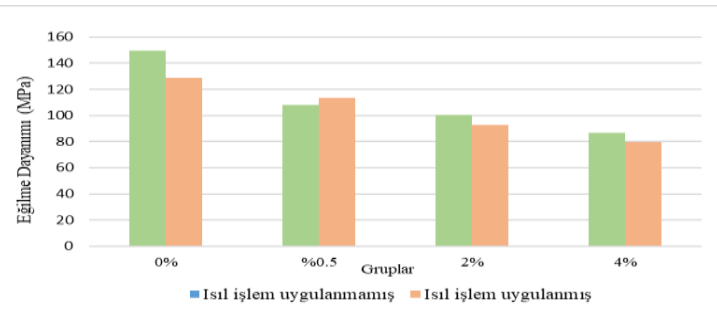

Şekil 1. Grupların eğilme dayanımlarının kıyaslanması

Isıl döngü işlemi uygulanan gruplarda ise; varyans analizinin sonuçlarına göre hem grup (ağırlık yüzdeleri) hem de ısıl döngü işlemi materyalin kırılma dayanımını etkilemektedir (Tablo 1) $(p<0.05)$. Gruplar arasında en yüksek eğilme dayanımı gösteren grup kontrol grubu $(128,47 \mathrm{MPa})$ iken, ağırlık yüzdesinin artması ile birlikte eğilme dayanımlarında azalma olduğu tespit edilmiştir. Ayrıca ısıl döngü işlemi bütün gruplarda eğilme dayanımını istatistiksel olarak anlamlı şekilde azaltmışırı $(p<0.05)$.

Tablo 1. Isıl döngü işleminin etkisinin değerlendirilmesi $(\mathrm{n}=10)$

\begin{tabular}{|c|c|c|c|c|c|}
\hline $\begin{array}{l}\text { Değişkenliğin } \\
\text { Kaynağı }\end{array}$ & & & & F-Deăeri & \\
\hline Grup & 3 & 39899,9 & 133000 & 68,88 & $0,000 *$ \\
\hline Isıl döngü & 1 & 3346,2 & 3346,2 & 17,33 & $0,000 *$ \\
\hline Grup*Isıl döngü & 3 & 487,5 & 162,5 & 0,84 & 0,476 \\
\hline Hata & 72 & 13903,1 & 193,1 & & \\
\hline Toplam & 79 & 57636,7 & & & \\
\hline $\begin{array}{l}\text { Varyans analizi so } \\
\text { farkllıkları gösterm } \\
\text { Freedom); SS: Ka }\end{array}$ & ler & plamı & um of & $\begin{array}{l}\text { istiksel olar } \\
\text { derecesi (L } \\
\text { quares); } \mathbf{M}\end{array}$ & $\begin{array}{l}\text { rak anlaml } \\
\text { Degrees of } \\
\text { पS: Kareler }\end{array}$ \\
\hline
\end{tabular}

\section{TARTIŞMA}

Protez kaidelerinin tekrar eden çiğneme kuvvetleri altında gösterdiği esneme özelliği nedeniyle oluşan internal stresler, akrilik polimerinde çatlak oluşumu meydana getirmekte ve bu çatlakların genişlemesiyle protez kırıkları ortaya çıkmaktadır. ${ }^{19} \mathrm{Bu}$ nedenle protez kaidelerinin kırık oluşumuna karşı direnç gösterebilecek yeterli dayanıma sahip olması gerekmektedir. Son yıllarda kaide materyallerinde çeşitli gümüş veya gümüş iyonu içeren inorganik doldurucuların gümüş-zeolit, gümüş-silika cam, gümüş- zirkonyum fosfat, gümüş-titanyumdioksit gibi farklı formlarda kullanılması ile rezinlere antimikrobiyal özellikler kazandırımıştır. ${ }^{15-17,20}$ Ancak ilave edilen modifiye edici ajanların antimikrobiyal avantajlarına rağmen kaide rezinlerinin mekanik özellikleri üzerine etkisinin de değerlendirilmesi gerekmektedir.

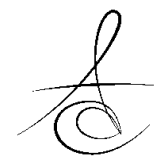


Sodagar ve arkadaşlarının ${ }^{20}$ yapmış olduğu bir çalışmada; \% 0,5 ve \% 0,1 oranında ilave edilen $\mathrm{SiO}_{2}$ ve $\mathrm{TiO}_{2}$ nanopartiküllerin akrilik rezinlerin eğilme dayanımını azaltığı rapor edilmiştir. Araştırmamızın sonuçlarına göre, eğilme dayanımdaki azalma Addy \& Handlery $^{21}$ ile Yadav ve arkadaşlarının ${ }^{22}$ yaptığı çalışmaların sonuçlarıyla da benzer olup, metakrilatlara ilave edilen mikrobiyal ajanların mekanik özellikleri zayıflattığı görülmüştür. Ayrıca akrilik rezine \% 5 oranında ilave edilen gümüş çinko zeolitin standartta belirtilen $65 \mathrm{MPa}$ dan daha düşük eğilme dayanımına neden olduğunu gösteren Yadav ve arkadaşlarının ${ }^{22}$ aksine sonuçlarımıza göre ilave edilen ajan oranı arttıkça eğilme dayanımı azalmasına rağmen bütün gruplarda standartta belirtilenden daha yüksek eğilme dayanımı değerleri saptanmıştır. Ayrıca ağrılık yüzdesinin artmasıyla eğilme dayanımının azalması, Shibate ve arkadaşları $^{23}$ ile Sodagar ve arkadaşlarının ${ }^{24,25}$ bulgularıyla da benzerdir. Eğilme dayanımındaki azalmanın polimerize olan rezinin internal yapısı üzerine nano boyuttaki oksitlerin etkisiyle oluştuğu düşünülmektedir. Ayrıca, ilave edilen nanopartiküllerin PMMA matriksinde dağılımı monomerlerin polimere dönüşümünü etkileyerek, plastizer olarak etki eden reaksiyona girmemiş artık monomerlerin artmasına neden olmaktadır. ${ }^{25}$ Bununla birlikte; akriliklere nano partiküllerin ilave edilmesi partiküllerin matriks içinde bir araya toplanıp kümeleşmesine neden olduğundan bu bölgeler stress yoğunlaşma bölgeleri oluşturmakta ve polimerize materyallerin mekanik özelliklerini zayıflatmaktadırlar. ${ }^{15,26} \mathrm{Bu}$ bulgulardan farklı olarak Kassaee ve arkadaşlarının $^{12}$ yaptığı çalışmada ise; \% 0,5 oranında gümüş nanopartiküllerin ilavesinin PMMA'ın eğilme dayanımında önemli bir etkiye neden olmadığı rapor edilmiştir.

Akrilik rezinlerin polimerizasyon tipleri de nanopartikül ilave edilen kaidelerin eğilme dayanımın etkileyen önemli faktörlerden biridir. ${ }^{25}$ Casemiro ve arkadaşlarının ${ }^{11}$ yapmış olduğu bir çalışmada 2 farklı ısıyla polimerize edilen rezinlere ve mikrodalga ile polimerize edilen rezine farklı oranlarda ( $\% 0, \% 2,5$, $\% 5, \% 7,5$ ve $\% 10$ ) ilave edilen gümüş-çinko zeolitin ısı ile polimerize olan rezinlerde çalışmamızın bulgularıyla benzer olarak, kontrol grubuyla kıyaslandığında eğilme dayanımını anlamlı şekilde azalttığı, mikrodalga ile polimerize olan rezin de ise, \% 2,5 oranında ilave edilmesiyle dayanımda anlamlı bir azalma olmadığı sadece $\% 5^{\prime}$ den daha büyük oranlardaki ilavelerin anlamlı şekilde eğilme dayanımını azalttığı tespit edilmiştir. Buna rağmen akrilik rezine $\% 2,5$ ve $\% 5$ oranında gümüş-zeolit ilave edilen gruplarda eğilme dayanımı ISO standart değerine uygun bulunmuştur. Eğilme dayanımdaki azalmanın zeolitin sahip olduğu poröz yapısından da kaynaklanabileceği göz önünde bulundurulmalıdır. ${ }^{22,27}$

Protez kaide rezinleri, oral çevrede özellikle sıcak ve soğuk gıdaların ve içeceklerin tüketilmesi sırasında rutin olarak termal streslere maruz kalırlar. Termal stresler polimer zincirleri arasındaki mesafeyi artırarak materyalin su emiliminin artmasına neden olabilmektedirler. Sıcaklık artışı su moleküllerinin kaide materyalleri içerisine daha hızı difüze olmasına sebep olmakta ve polimer içerisindeki su plastizer olarak etki göstererek çiğneme kuvvetleri altında zincirlerin birbiri üzerinden çok daha kolay kaymasına izin vermekte ve bu durum polimerlerin mekanik özelliklerini negatif yönde etkilemektedir. ${ }^{28,29}$

Sulu ortamda rezin matrikste bulunan çeşitli partiküllerin (artık monomer, modifiye edici ajanlar ve plastize edici ajanlar vb.) zamanla çözülerek uzaklaşması nedeniyle oluşan porözite ve artan su emilimi de eğilme dayanımını azaltabilmektedir. ${ }^{14,21}$ Aynı zamanda emilen su molekülleri materyallerin hafifçe genişlemesiyle protez kaide rezinlerindeki çatlakların oluşmasına neden olabilmektedir. ${ }^{30}$ Feng ve arkadaşları ${ }^{14}$ ile Kawaguchi ve arkadaşları ${ }^{30}$ da sonuçlarımızla uyumlu olarak 6 ay distile su da bekletilen 4 farklı Isıyla polimerize olan akrilik rezinin eğilme dayanımlarının kontrol grubuyla kıyaslandığında anlamlı şekilde azaldığını rapor etmişlerdir. Machado ve arkadaşlarının $^{31}$, 5000 ısıl döngü uygulanan ve uygulanmayan yüksek dayanımlı ısı ile polimerize akrilik rezinler ile ISı ile polimerize poliüretan protez kaide materyallerinin eğilme dayanımlarını kıyasladıkları çalışmalarında, ısıl döngü işleminin her iki materyalinde eğilme dayanımlarını istatiksel olarak anlamlı derecede azalttığını rapor etmişlerdir. Çalışmamızda, ısıl döngü işleminin bütün gruplarda önceki çalışmaların sonuçlarıyla benzer olarak eğilme dayanımını azaltığı ve mekanik özelliklerinin zayıflamasına neden olduğu tespit edilmiştir. Bu bulgulardan farklı olarak Ayaz ve arkadaşları ${ }^{32}$ ise, ısıl işlemin PMMA ve poliamid esaslı kaide materyallerinin fiziksel ve mekanik özellikleri üzerinde anlamlı bir etkisi olmadığını rapor etmişlerdir. Isıl döngü işleminin neden olduğu mekanik değişimlerin klinik açıdan yaratacağı etkilerin daha ileri araştırmalarla desteklenmesi gerekmektedir. ${ }^{33,34}$ 
Araştırmamızın sonuçlarına göre; düşük yüzdelerde akrilik rezinlere ilave edilen zeolitlerin mikroorganizmalara karşı etkili olabilmesi nedeniyle özellikle protezlerini yeteri kadar temizleyemeyen hastalarda mekanik özellikler üzerindeki etkisi daha az önemli olabilmektedir. Nitekim sonuçlarımıza göre; en fazla \% 4 oranında ilave edilen zeolitin akriliğin mekanik özelliğini standart kabul edilen sınırın üstünde bir değere kadar zayıflattığı tespit edilmiştir. Zeolitin akriliklere ilavesinde, klinik açıdan hasta memnuniyetini etkileyecek olan tek olumsuz faktör ise PMMA' in opaklığının artmasıdır ve ilave edilen oran arttıkça opaklık daha fazla artmaktadır. ${ }^{35}$ Zeolitin neden olduğu bu translusensideki azalmanın önüne geçilebilmesi için daha fazla çalışma yapılması gerekmektedir.

\section{SONUÇLAR}

1. Mikrobiyal ajanların ilavesinde ağrılık yüzdesinin artmasına paralel şekilde eğilme dayanımı da azalmaktadır.

2. Isıl döngü işlemi protez kaidelerinin eğilme dayanımlarının anlamlı şekilde azalmasına neden olmuștur.

Clıkar catıssması: Bu makale yazarının makalede bahsi geçen konu ve malzemeyle ilgili herhangi bir ilișkisi, bağlantısı veya parasal cılkar durumu söz konusu değildir.

Tessekkür ve anma: Yazar çalıșmanın istatistiksel analizlerin gerçekleștiren Sn. Tümer Arıtürk'e minnettarlığını ve saygıların iletmektedir.

Sema Murat: ORCID ID: 0000-0003-0632-5095

\section{KAYNAKLAR}

1. Goiato M, Santos D, Haddad M, Pesqueira A. Effect of accelerated aging on the micro hardness and color stability of flexible resins for dentures. Braz Oral Res 2010;24:114-9.

2. Korkmaz FM, Bağış B, Ayaz EA, Turgut $S$, Ateş SM, Tuzumer $\mathrm{T}$ : Effect of lazer treatments on the strenght of denture base repair. J Dent Fac Atatürk Uni 2014;24:74-80.

3. Jagger $D$, Harrison $A$, Jagger $R$, Milward $P$. The effect of the addition of poly (methyl methacrylate) fibres on some properties of high strength heatcured acrylic resin denture base material. J Oral Rehabil 2003;30:231-5.

4. Radford DR, Challacombe SJ, Walter JD. Denture plaque and adherence of Candida albicans to denture-base materials in vivo and in vitro. Crit Rev Oral Biol Med 1999;10:99-116.
5. Keng SB, Lim M. Denture plaque distribution and the effectiveness of a perborate-containing denture cleanser. Quintessence Int 1996;27:341-5.

6. Milenkovic J, Hrenovic J, Matijasevic D, Niksic M, Rajic N: Bactericidal activity of $\mathrm{Cu}-, \mathrm{Zn}-$, and $\mathrm{Ag}$ containing zeolites toward Escherichia coli isolates. Environ Sci Pollut Res Int 2017;24:20273-81.

7. Abe Y, Ishii M, Takeuchi M, Ueshige S, Tanaka S, Akagawa $Y$. Effect of saliva on an antimicrobial tissue conditioner containing silver-zeolite. J Oral Rehabil 2004;31:568-73.

8. Jo JK, El-Fiqi A, Lee JH, Kim DA, Kim HW, Lee HH. Rechargeable microbial anti-adhesive polymethyl methacrylate incorporating silver sulfadiazineloaded mesoporous silica nanocarriers. Dent Mater 2017;33:e361-e72.

9. Chen R, Han Z, Huang Z, Karki J, Wang C, Zhu B, Zhang X. Antibacterial activity, cytotoxicity and mechanical behavior of nano-enhanced denture base resin with different kinds of inorganic antibacterial agents. Dent Mater ] 2017;36:693-99.

10. Oyar P. Nanoparticles in dentistry, their applications, and biocompatibility. J Dent Fac Atatürk Uni 2014;24:125-133.

11. Casemiro LA1, Gomes Martins $\mathrm{CH}$, Pires-de-Souza Fde $\mathrm{C}$, Panzeri $\mathrm{H}$. Antimicrobial and mechanical properties of acrylic resins with incorporated silverzinc zeolite - part I. Gerodontology 2008;25:18794.

12. Kassaee M, Akhavan A, Sheikh N, Sodagar A. Antibacterial effects of a new dental acrylic resin containing silver nanoparticles. J Appl Polym Sci 2008;110:1699-703.

13. Ghaffari T1, Hamedi-Rad F. Effect of Silver Nanoparticles on Tensile Strength of Acrylic Resins. J Dent Res Dent Clin Dent Prospects 2015;9:40-3.

14. Feng D, Gong H, Zhang J, Guo X, Yan M, Zhu S. Effects of antibacterial coating on monomer exudation and the mechanical properties of denture base resins. J Prosthet Dent 2017;117:171-7.

15. de Castro DT, Valente ML, Agnelli JA, Lovato da Silva $\mathrm{CH}$, Watanabe E, Siqueira RL, Alves OL, Holtz $\mathrm{RD}$, dos Reis AC. In vitro study of the antibacterial properties and impact strength of dental acrylic resins modified with a nanomaterial. J Prosthet Dent 2016;115:238-46.

16. Wady AF, Machado AL, Zucolotto V, Zamperini CA, Berni E, Vergani CE. Evaluation of Candida albicans adhesion and biofilm formation on a denture base 
acrylic resin containing silver nanoparticles. J Appl Microbiol 2012;112:1163-72.

17. Ferreira L, Guedes JF, Almeida-Aguiar C, Fonseca AM, Neves IC. Microbial growth inhibition caused by $\mathrm{Zn} / \mathrm{Ag}-\mathrm{Y}$ zeolite materials with different amounts of silver. Colloids Surf B Biointerfaces 2016;142:141-7.

18. International Organization for Standards. Dentistry-Base polymers -Part 1: Denture base polymers. ISO 20795.

19. Sato S, Cavalcante MRS, Orsi IA, Zaniquelli O. Assessment of flexural strength and color alteration of heat-polymerized acrylic resins after simulated use of denture cleansers. Braz Dent J 2005; 16:124-8.

20. Sodagar A, Khalil S, Kassaee MZ, Shahroudi AS, Pourakbari B, Bahador A. Antimicrobial properties of poly (methyl methacrylate) acrylic resins incorporated with silicon dioxide and titanium dioxide nanoparticles on cariogenic bacteria. J Orthod Sci 2016;5:7-13.

21. Addy M, Handley R. The effects of the incorporation of chlorhexidine acetate on some physical properties of polymerized and plasticized acrylics. J Oral Rehabil 1981;8:155-63.

22. Yadav NS, Saraf S, Mishra SK, Hazari P. Effects of fluconazole, chlorhexidine gluconate, and silverzinc zeolite on flexural strength of heat-cured polymethyl methacrylate resin. J Nat Sci Biol Med 2015;6:340-2.

23. Shibata T, Hamada N, Kimoto K, Sawada T, Sawada T, Kumada $H$, Umemoto $T$, Toyoda $M$. Antifungal effect of acrylic resin containing apatitecoated $\mathrm{TiO} 2$ photocatalyst. Dent Mater J 2007;26:437-44.

24. Sodagar A, Kassaee M, Akhavan A, Javadi N, Arab $S$, Kharazifard $M$. Effect of silver nano particles on flexural strength of acrylic resins. J Prosthodont Res 2012;56:120-4.

25. Sodagar A, Bahador A, Khalil S, Shahroudi AS, Kassaee MZ. The effect of $\mathrm{TiO} 2$ and $\mathrm{SiO} 2$ nanoparticles on flexural strength of poly (methyl methacrylate) acrylic resins. J Prosthodont Res 2013;57:15-9.

26. Han Y, Kiat-amnuay S, Powers JM, Zhao Y. Effect of nanooxide concentration on the mechanical properties of a maxillofacial silicone elastomer. ] Prosthet Dent 2008;100:465-73.

27. Mutneja P. Flexural strength of heat cure acrylic resin after incorporating different pertentages of silver zinc zeolite an in-vitro study. Int J Clin Cases Investig 2012;25:31.

28. Takahashi Y, Hamanaka I, Shimizu H: Effect of thermal shock on mechanical properties of injection-molded thermoplastic denture base resins. Acta Odontol Scand 2012;70:297-302.

29. Singh RD, Gautam R, Siddhartha R, Singh BP, Chand P, Sharma VP, Jurel SK. High performance liquid chromatographic determination of residual monomer released from heat-cured acrylic resin. An in vivo study. J Prosthodont. 2013;22:358-61.

30. Kawaguchi T, Lassila LV, Sasaki H, Takahashi $Y$, Vallittu PK. Effect of heat treatment of polymethyl methacrylate powder on mechanical properties of denture base resin. J Mech Behav Biomed Mater 2014;39:73-8.

31. Machado AL, Puckett AD, Breeding LC, Wady AF, Vergani CE. Effect of thermocycling on the flexural and impact strength of urethane-based and highimpact denture base resins. Gerodontology 2012;29:e318-23.

32. Ayaz EA, Bağış B, Turgut S. Effects of thermal cycling on surface roughness, hardness and flexural strength of polymethyl methacrylate and polyamide denture base resins. J Appl Biomater Funct Mater 2015;13:e80-6.

33. Silva Cde $S$, Machado AL, Chaves Cde A, Pavarina $A C$, Vergani CE. Effect of thermal cycling on denture base and autopolymerizing reline resins. J Appl Oral Sci 2013;21:219-24.

34. Köroğlu A, Şahin O, Kürkçüoğlu I, Dede DÖ, Özdemir T, Hazer B. Silver nanoparticle incorporation effect on mechanical and thermal properties of denture base acrylic resins. J Appl Oral Sci 2016;24:590-6.

35. Sato S, Cavalcante MRS, Orsi IA, Zaniquelli O. Assessment of flexural strength and color alteration of heat-polymerized acrylic resins after simulated use of denture cleansers. Braz Dent J 2005;16:124-8.

\author{
Yazışma Adresi \\ Dr. Sema Murat \\ Ankara Üniversitesi Diş Hekimliği Fakültesi \\ Protetik Diş Tedavisi Anabilim Dalı \\ Beşevler/ Ankara/Türkiye 06500 \\ Tel:05396723751 \\ Email: smurat@ankara.edu.tr
}

